\title{
ALTRIRAS: A Computer Game for Training Children with Autism Spectrum Disorder in the Recognition of Basic Emotions
}

\author{
Leandro M. Almeida, Diego P. da Silva (D), Daieny P. Theodório, \\ Wolley W. Silva, Silvia Cristina M. Rodrigues $(\mathbb{D}$, Terigi A. Scardovelli $(\mathbb{D}$, \\ Alessandro P. da Silva, and Marcia Aparecida S. Bissaco $\mathbb{D}$ \\ Technological Research Center, University of Mogi das Cruzes, 08780-911 Mogi das Cruzes, SP, Brazil \\ Correspondence should be addressed to Marcia Aparecida S. Bissaco; mbissaco@gmail.com
}

Received 4 October 2018; Revised 7 February 2019; Accepted 5 March 2019; Published 2 May 2019

Academic Editor: Ali Arya

Copyright (C) 2019 Leandro M. Almeida et al. This is an open access article distributed under the Creative Commons Attribution License, which permits unrestricted use, distribution, and reproduction in any medium, provided the original work is properly cited.

\begin{abstract}
This paper presents a computer game developed to assist children with Autism Spectrum Disorder (ASD) to recognize facial expressions associated with the four basic emotions: joy, sadness, anger, and surprise. This game named ALTRIRAS is a roleplaying game (RPG), a kind of game pointed out by the literature as the most suitable for these children for being more social than competitive. It has recreational settings built with $2 \mathrm{D}$ graphic interface to keep the children's attention and an access control and a register mechanism to allow the monitoring of the child's progress. The data collection of the functional, nonfunctional, psychological, and educational requirements, as well as the evaluation of its consistency and usability, was made by a multidisciplinary team consisting of five experts in each of the following expertises: pedagogy, psychology, psychopedagogy, and game development. The effectiveness test of the game was performed by 10 children with ASD and 28 children with neurotypical development, which were separated into control and experimental groups, respectively. All experts and children with neurotypical development answered the System Usability Scale (SUS) questionnaire after playing the game. The results were positive, between experts and volunteers regarding their acceptance. However, the time of exposure to the game in children with ASD should be increased to effective assistance in the recognition of facial expressions.
\end{abstract}

\section{Introduction}

The Autism Spectrum Disorder (ASD) is a neurodevelopmental disorder associated with several aetiologies and with different degrees of severity. Its main characteristics are difficulty of understanding other people's facial emotions and social interaction, body language recognition, eye contact, language domain to communicate themselves in the verbal and nonverbal forms, and a restrictive and repetitive behaviour standard and sensorial processing, such as sensibility to the sound, vision, and touch [1-9].

This disorder does not choose social condition and demographic roots; its gender incidence is five times greater in boys; it is estimated that it affects one boy for every 54 births, while the number is significantly lower for females, having an incidence of one for every 252 girls. In Brazil, according to studies carried out by the ABRA-Brazilian
Autism Association - there must be two million autism cases $[10,11]$.

Children with ASD present deficit in the ability of recognizing emotions and facial expressions, thus affecting directly their cognitive skills, responsible for the social interaction, expressive behaviour, and personality [12-18]. However, early intervention and personalized treatment can help these children to cope with it better [4].

Looking at a person's face it is possible to detect the gender, age, and mood in fractions of seconds [16,19]. Usually, children with ASD pay attention to the details of another person's body or object, especially those in motion. Despite children being attentive, they are unable to understand the set of information provided in front of them [20].

Over the years, many studies have been done to aid people with autism to better relate to and cope with our modern society. Technological advances in games have also 
been developed for helping children with ASD in their social, communicative, and vocabulary skills and in their learning process $[6,21,22]$.

Computer and console games specifically designed for educational and training purposes have been introduced in the psychotherapy field $[6,24,25]$. It is possible to use these games privately in rehabilitation sections since they serve as an evaluating tool for the processes of attention, perception, cognitive skills, among others [26-28].

There are some applications that help children train the association of emotions with facial expressions. These applications usually follow a pattern; they usually show the image or the design of a face expressing the basic emotions. From these images, the user must inform the type of emotion that he/she believes to be represented. There are also applications that associate the sound of a feeling with your image, such as Tough-Emotions, an application developed by Special iApps, which shows in the cartoon format, random facial expressions, to select emotions [29]. Another application is Emotions from Grasshopper Apps, which uses photos of people with various facial expressions. The purpose of Emotions is to associate the same images. Although it is easy to play, it is not very interactive because its main feature is the association [30].

The LIFEisGame application is a $3 \mathrm{D}$ game that maps the user's face, the application scores for each correct expression [29]. This game allows only facial expressions without stimulating other skills, such as nonverbal language.

Treatment techniques for ASD such as Image Exchange Communication System (PEC), Applied Behaviour Analysis (ABA), and Treatment and Education of Children with Autism and Communication (TEACCH) can be adapted to the format of computer games to provide cognitive development and improve learning process [22, 31]. Children with ASD who used these applications and games in the learning process presented considerable development in school [32].

Despite having the applications mentioned above, there is still a need for creating new computer tools to work the skills of children with ASD to recognize and respond to emotions by facial expressions. This activity may enhance the communicative and social skills, complementing the advancements made by the family and the inclusive education professionals. Therefore, the main objective of this study is to create a roleplaying game to help these children to recognize different facial expressions and emotions.

\section{Materials and Methods}

The game described below was named ALTRIRAS as a reference to the basic emotions, namely, ALegria (joy), TRIsteza (sadness), RAiva (anger), and Surpresa (surprise). It was designed to help literate or nonliterate children with ASD aged between six and 12 to associate these basic emotions to the corresponding facial expressions.

According to Assumpção et al. [20], such basic emotions are essential for the understanding of other more complex emotions. They are also relevant for the socializing and communication process, according to the literature and assessment of a multidisciplinary team and should be acknowledged throughout the game.

The game's story presents the adventures of Rex (male) or Tina (female), the main character, that is training another character named Emotion. During the game the character must collect items (parts of facial expressions) and when a challenge appears (puzzle) the character must use the collected items to assemble the requested facial expression in the challenge.

The game presents different tasks with puzzle-solving tracks. It is set in a 2D medieval and contemporary scenario with high quality graphics in three kinds of scenarios: forest, desert, and woods with increasing challenging levels. To finish each phase, the player must complete the puzzles of each environment, build the facial expressions corresponding to the emotions, and avoid the enemy traps (wasps, slime, bones, warthogs, bats, and goblins). At the same time, the player has to gather emotions to upgrade the character Emotion. At the end of the puzzle, a feedback screen shows the player its score and the next puzzle. This strategy will be used until the end of the game and the time limit is 300 seconds.

During the game development, international quality software concepts were observed, according to the ISO/IEC 9126 regulation, which takes into account the quality of the internal and external use of the software and the user's opinion about it. The ISO/IEC 14598 regulation was also noted which relates to the software evaluation by the main characteristics of the process (reproducibility, impartiality, repeatability, and objectivity).

2.1. Software Development. The game ALTRIRAS was created considering the interactive life cycle, in which surveys analysis and project, implementation, and final tests were executed $[33,34]$.

The requirements were gathered with the help of a multidisciplinary team (kindergarten educators, psychologists, computer experts, and biomedical engineers), as mentioned in the literature $[33,34]$. Interviews were conducted with the multidisciplinary team of the Municipal Department of a city in the Alto Tietê region, in the state of São Paulo, responsible for the Special Education Assistance (AEE) classrooms.

After that, the functional and nonfunctional requirements were listed. The prototypes and diagrams were modelled using the Unified Modelling Language (UML), in accordance with Sommerville [33]. Figures 1 and 2 show the use case diagram (DCU) and activity diagram of the game ALTRIRAS, respectively. DCU shows a static vision while activity diagram presents a dynamic vision of the game functions.

The Game Design Document (GDD) describes technical, artistic, and descriptive features, such as plot, game engine, objective, gameplay benefits, and development tools. The main characters were designed in a cartoon style, considering most physical traits of a dinosaur, but keeping childlike features. The characters' movements were modified to enhance gestures as well. Additionally, the psychologists, who participated of the requirements survey, suggested the use of the character Emotion. This character shows only the facial expressions aiming to decrease the distractor elements. 


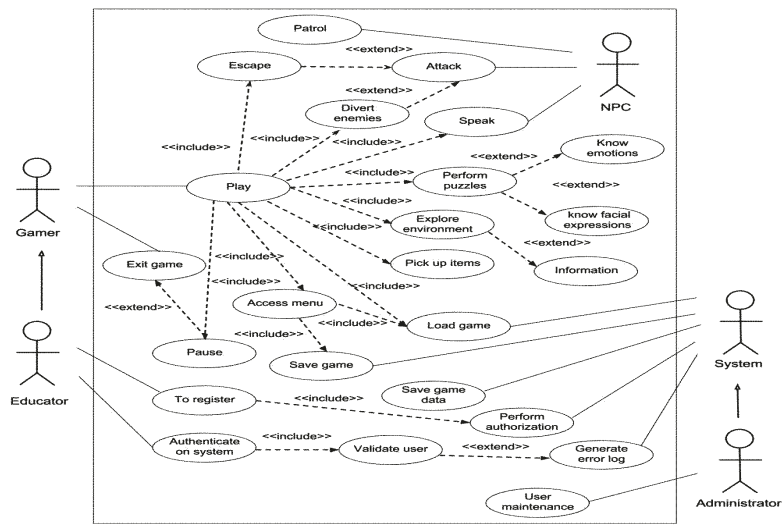

FIGURE 1: Use case diagram of ALTRIRAS game.

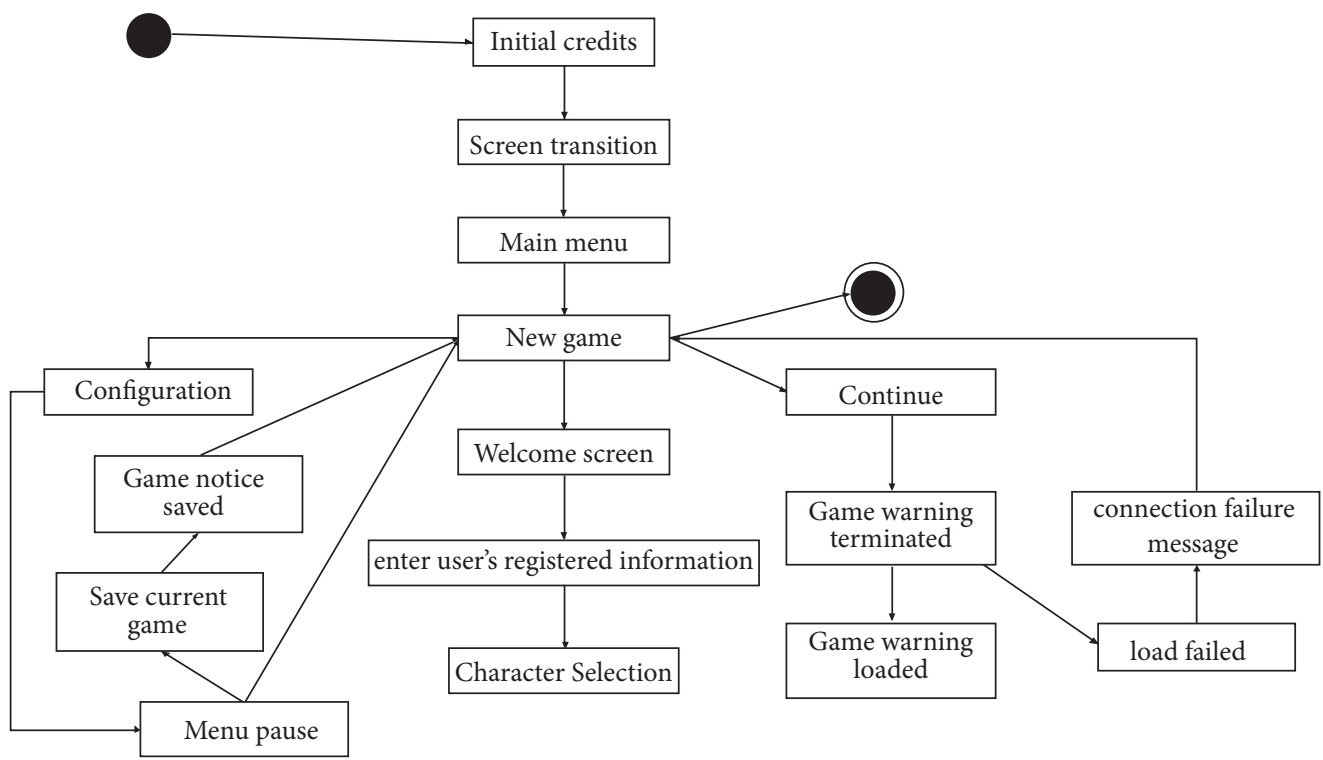

Execution of the game

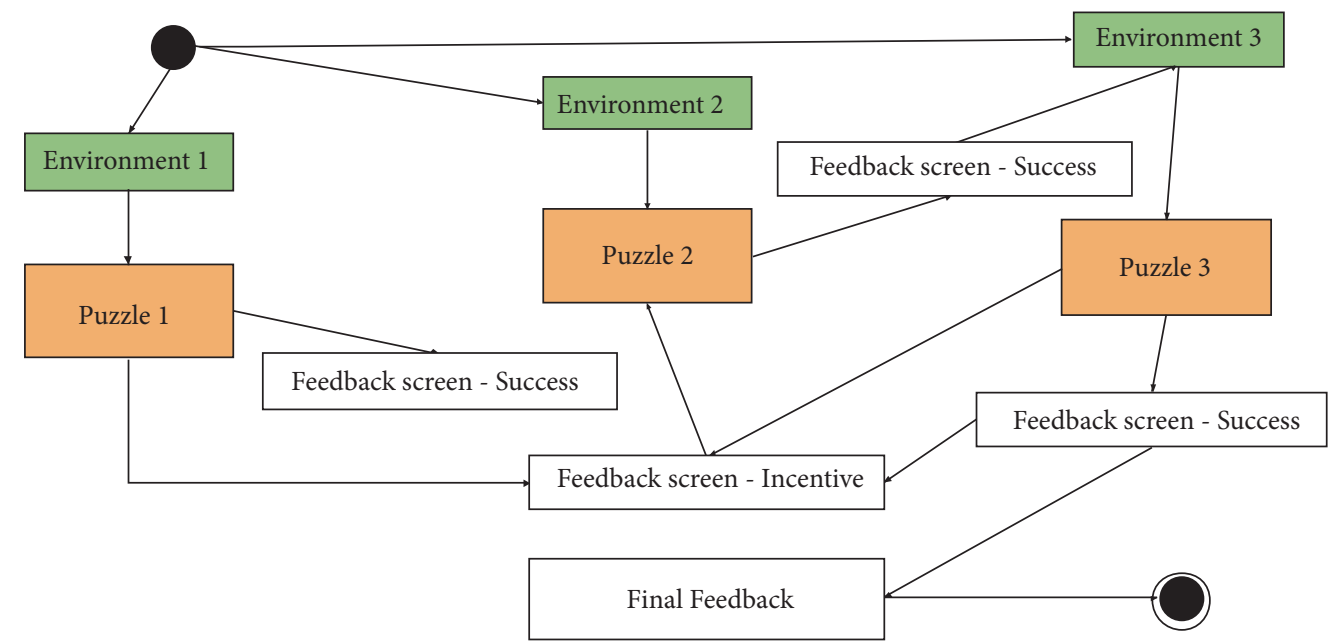

Figure 2: Activity diagram of ALTRIRAS game. 
The game ALTRIRAS was developed to explore imagination. For that, the Emotion character was designed in order to not understand any emotions in the beginning of the game. During the game it is necessary to train it to recognize the emotions associated with the facial expressions. The emotion coach (Rex or Tina) is the only one able to teach basic emotions to Emotion character. From that moment on, the character must defeat the thieves of emotions (characters of the dark forest) in order to maintain the peace in this kingdom.

The player must accumulate parts of the facial expressions (eyes, mouth, and eyebrows) corresponding to the emotions, avoid being caught by the enemies, escape from traps, and gather emotions to upgrade the skills of the Emotion character. The gameplay is based on the path that Rex or Tina must follow until the accomplishment of each puzzle. When the feedback screen pops up the next puzzle begins, until the end of the game. Feedbacks were given according to Laitinen [35].

Graphical interfaces and interactivity mechanisms were implemented considering the resources that define a computerized game. The entire environment was modelled with 2D interface and isometric graphics.

The game coding was performed so that all analysis functions were transferred to the Microsoft Visual Studio 2015 software command interpreter for Unity 3D through the C-Sharp programming language $(\mathrm{C} \mathrm{\# )}$ and Hypertext Preprocessor (PHP). PaintTool SAI Ver.1 and AutoDesk SketchBook Pro software were used to create images of the characters and environments and their vectorization. Illustrator CC software was used to vectorize the sketches and colourization. The textures and images were generated in the Joint Photographics Experts Group (JPEG) format. Graphics Interchange Format (GIF) images were little used because they did not have the same quality as vector images. For the background of some environments, the software Photoshop CC was used.

In the modelling and colourization of the characters, the software Illustrator CC and Photoshop CC were used. All character models have followed the standards of their model sheets. In modelling of the scenarios and objects of the virtual environment, the software PaintTool SAI Ver.1, Photoshop $\mathrm{CC}$, and Illustrator CC were used.

The animations and logic of each learning object, as well as the character, were developed with Brashmonkey's Spriter Pro and exported to Unity 3D. The motion effect was generated by sprite sheet, with modular images using bones and their interpolation.

The game was designed for web. The MySQL database (Oracle Corporation) was also used to allow the creation of a login and password system, following the standard project Model-View-Controller (MVC) and Singleton allowing the player to access and continue from where the game stopped.

The player must use the mouse and keyboard to interact with the game. With the keyboard it is possible to perform the movements of the character, to change the types of emotions, and to access the control of the interface.

The initial interface has been coded so that the player can access the options "New Game", "start a new match", and "choose the character (Rex or Tina)". The player is encouraged by positive feedbacks displayed in written messages, sounds, and pictures. Feedbacks are released at the most advanced levels to improve self-esteem. When completing a puzzle, for example, the character's energy bar is filled again. The progression of the game depends on the conclusion of the puzzles and the accumulation of items of each environment. Feedbacks are displayed at the end of the task because even if the child cannot complete, he or she should be encouraged. All instructions in the game are both narrated and written in the lower part of the screen.

The elements in the screen were distributed as follows: emotion bars (inform the quantity of each item); field (indicates number of potions); map and radar (show the player's position and enemies on the way); hint bar (informs item position); and field of emotions (indicates the number of items collected.

2.2. Evaluation of the Game. The consistency of the game has been verified through software tests carried out by the authors, who observed usability, functionality, navigation, and gameplay, as well as through the expert assessment and effectiveness test performed by children with and without ASD.

All procedures involving human subjects were approved by the Research Ethics Committee of the University of Mogi das Cruzes (CAAE: 57356916.2.0000.54970, Process CEP/UMC-2016, 1.621.38700). Participants were invited and enlightened about the research objectives and signed the Informed Consent Term.

ISO/IEC 14598 and ISO/IEC 14598 guidelines have also been considered for testing the white box and black box as well as the usability test $[36,37]$. The case-control protocol was developed considering aspects of usability, communicability, navigability, and reliability according to the literature $[35,38,39]$. The usability test covered few metrics, namely, graphics, sound, control, fun, and animation. Possible errors were analysed along with browsing difficulty levels, sound, and visual assets as informed in the literature [35, 38]. Additionally, all experts and non-disabled children also answered the System Usability Scale (SUS) questionnaire after playing the game.

The SUS questionnaire contains questions about ease of learning, efficiency, ease of memorization, occurrence of execution errors, and level of satisfaction. That is, this questionnaire contains 10 statements whose answers are based on the five-point scale in order to assess the level of agreement of the volunteers who performed the game, and the level of agreement varies from one (totally disagree) to five (totally agree) [38-41].

The experimental procedures and research participants were described below.

2.3. Expert Assessment. A multidisciplinary team consisting of experts in pedagogy, psychology, psychopedagogy, and game development, five of each field, played the game ALTRIRAS and also commented on its pedagogical, psychological, and recreational requirements. Nielsen's study of usability assessment was taken into account to determine the 
number of experts by expertise [39]. The experts played the ALTRIRAS at their preferred time and place and also took the time they needed to perform all the functions of this game. Also, they observe whether there were implemented characteristics related to each expertise in it. Afterwards, they did some remarks or suggestions. The SUS questionnaire and few standardized questions were also available to help their decision in which were listed aspects like gameplay, browsing, communicability, and reliability, as well as its development features described below. Educators have checked if the codified educational content in the game covered the language skills established by the Ministry of Education and Culture (MEC) for special education classrooms, where children with ASD have lessons in Brazil, if the playful characteristics implemented will encourage logical thinking and memory skills and, finally, if they will assist these children in the emotion learning process.

Psychologists have taken into account the existence of rules and limits in the game if win or loss situations are presented to the player, if he/she deals with frustration in a positive manner, and finally if the functional requirements introduced are capable of encouraging children with ASD to accomplish the activities in which the ability to identify facial expressions and their emotions is necessary.

Psychopedagogues have evaluated whether or not the game presents challenges towards the emotion learning process by verifying if the enabling elements of the learning process are aligned with ASD characteristics.

The experts in system development, electronic, and educational games have reviewed the features presented in the game, such as gameplay and the interface similarity with commercial games of entertainment, script, fantasy, characters, sound, interactivity, etc.

2.4. Effectiveness Test with Children. To perform the ALTRIRAS effectiveness test, it was invited a total of 40 children of both sexes aged three to 13 years old, who were studying at two schools located in the city of São Paulo Metropolitan Region, state of São Paulo, Brazil, being one school from the city's municipal education system which covers special education for children with intellectual disability, while the other is from the private school system. Both schools have Specialized Educational Environment classrooms. In this case, an authorization was obtained from the city's education secretary.

Two children with neurotypical development (i.e., nondisabled children) were excluded because their parents have not returned the free and informed consent form signed to us. Therefore, the effectiveness test was only performed by 10 children with ASD from the city's municipal education system and 28 non-disabled children from a private school, whose parents gave us the signed consent form. Afterward, they were separated into experimental (EG) and control (CG) groups, respectively.

According to the information provided by multidisciplinary teams from the both schools, all children enrolled in this study had a similar socioeconomic level and the same learning opportunities; computer literacy; already used computerized game in the school's computer classroom.
However, while the children with ASD were from middle to low-SES families, non-disabled children were from middle to high-SES families.

The sample size was limited to the total number of children who attended the two schools involved with our study. All subjects met the inclusion criteria mentioned above.

The number of subjects and protocols employed in this study are shown in the flow diagram of Figure 3 and described below.

All children used software named QuizEmotion before (pretest) and after (pretest) the intervention period with the game ALTRIRAS, whose results were compared in order to verify if the game changes the participant's performance in the identification of the facial expressions of the feelings of joy, sadness, anger, and surprise.

QuizEmotion was developed by the author in order to show the user only five sets of images containing four facial expressions, which correspond to the four basic emotions (i.e., joy, sadness, anger, and surprise), in an aleatory manner.

The children performed the pretest in a 30 min session. Afterward, there was the intervention phase, where the game "Adventures in the Kingdom of ALTRIRAS" was presented to each of the children. Then the posttest was performed in a 30 min session as well.

The pretest and posttest were carried out with the children in a suitable place, calm, and familiar to the each of them, specially reserved for the test in the school's AEE classrooms for children with ASD and in the computer classroom for non-disabled children. In the first case, both tests were applied by the psychologist herself who already works with these children in the day-to-day life of the school. On the other hand, for non-disabled children the procedure was applied by one of the study's collaborators in their school's computer classroom.

During the intervention phase, the children were taken to the computer classroom being aware that they would play and use a computer game. The time for performing the game was 60 minutes per session, once a week for four weeks. Additionally, the children continued the traditional activities at their school.

Moreover, the children's behaviour was observed and recorded during the interaction with the situations experienced in the game, such as presented difficulties to start the game, verbalized positively about the game, demonstrated interest in interactive activities, requested help, learned to use the controls easily, distracted themselves with external stimuli, requested extension of the preestablished time, played without stopping, and wanted to play again. The subjects were also questioned by the researcher if they owned a computer at home and were used to playing games to relate the recorded difficulties to the lack of motor coordination when using the mouse or keyboard.

2.5. Data Analysis. The qualitative results, assessed from the evaluation performed by experts, were measured through descriptive statistical analysis. The average of the answers of the collaborating specialists was calculated and the 


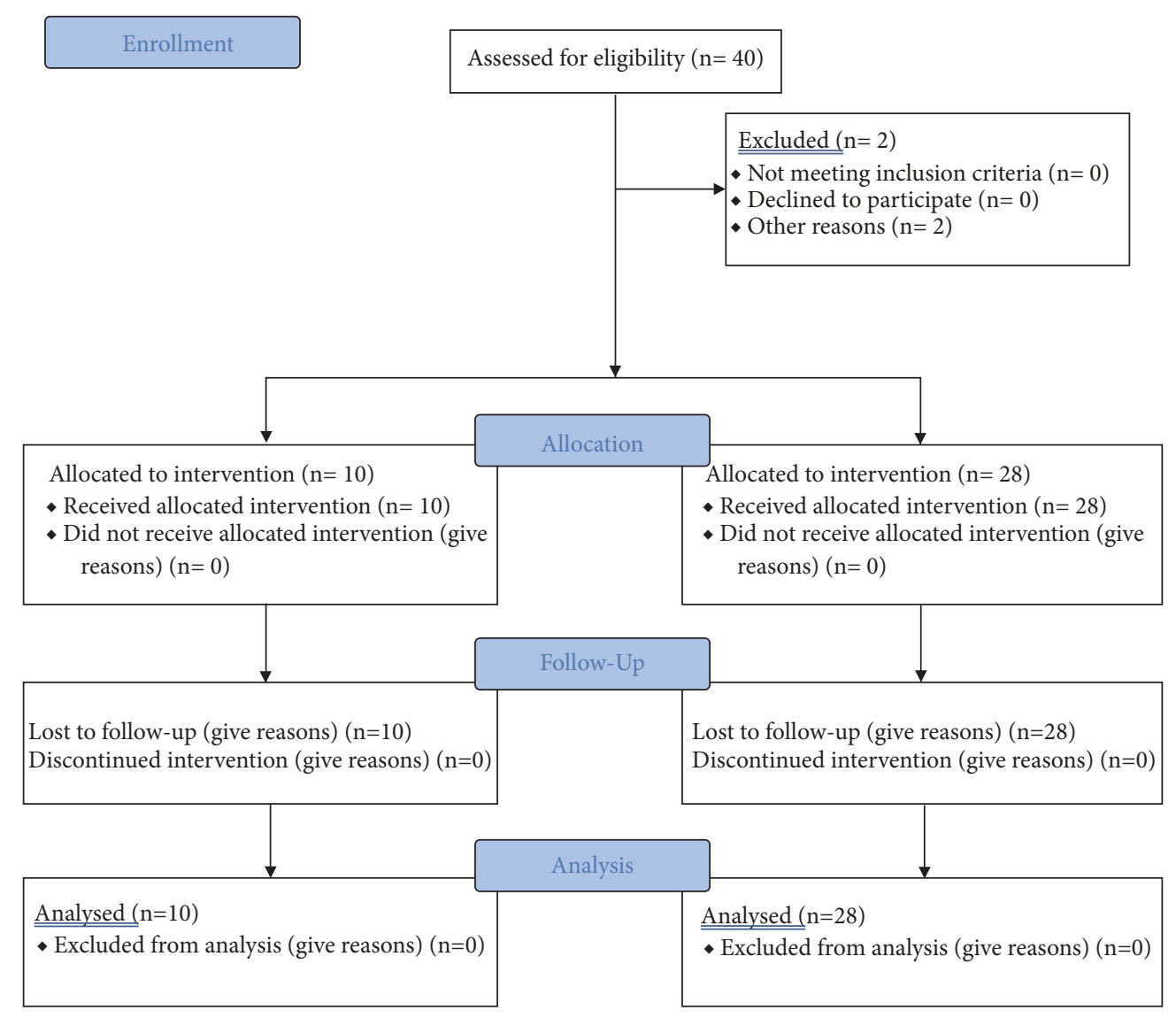

Figure 3: Flow diagram: Consort and Tren.

quality component was analysed. The Likert scale was also applied to the questionnaires used in the usability test in order to minimize the subjectivity of the qualitative data.

Regarding the application of pre- and posttests, the initial and final performance of both groups of children were compared to verify if the game altered the participant's performance in identifying the facial expressions of feelings of joy, sadness, anger, and surprise. Thus, the normality test was applied to the quantitative results to verify if the distribution was parametric. To verify the effectiveness of the developed game, the Kruskal-Wallis statistical test was applied. This statistical test was applied to compare the results obtained with the QuizEmotion app used by children with and without TEA before the intervention with the game ALTRIRAS, because the data are not parametric. Statistical posttest was also applied using the Student-Newman-Keuls test. To compare the results obtained for children with ASD, before and after the intervention, Wilcoxon's statistical test was used. For this, we used the software Bioestat v.5.3. with a significance level of 0.05 .

The data obtained with the SUS questionnaire were evaluated by adding the contributions of the scores of each item. Each score contribution of the item ranges from zero to four. For statements Q1, Q3, Q5, Q7, and Q9 (positively expressed) the contribution of the score is the position of the scale (from one to five) minus one. For the statements Q2, Q4, Q6, Q8, and Q10 (negatively) the contribution is five minus the position of the scale. Then the sum of the scores was multiplied by two and a half to obtain an overall system usability score ranging from zero to 100.

As performed by $[23,42,43]$, the software quality components indicated by Nielsen [39] were also recognized through this SUS score, which are related to the ease of use and that correspond to the questions:

(i) 5, 6, and 8: efficiency: how fast the user can accomplish a task after learning to use the interface;

(ii) 2: ease of memorization: when the user returns to the interface after a period of no use, how easily can it establish the same competence already achieved;

(iii) 6: minimization of errors: level of seriousness of the mistakes made by the user and how easily the system can recover from them;

(iv) 1, 4, and 9: satisfaction: how pleasant is the use of the interface;

(v) 3, 7, and 10: ease of learning: how easy it is for the user to perform simple tasks using the interface for the first time.

The conversion of the scores obtained through the SUS scale into adjectives, which express the usability of the system, was performed as proposed in the study of the Bangor et al. [41]. 


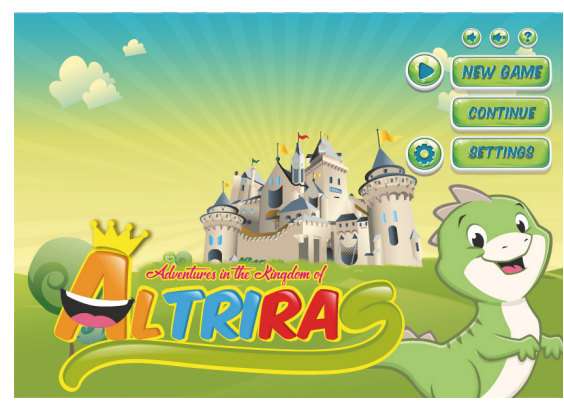

FIgURE 4: Home interface.

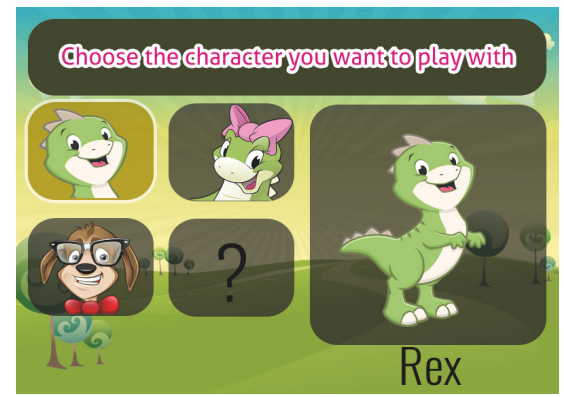

Figure 5: This interface allows the selection of the character.

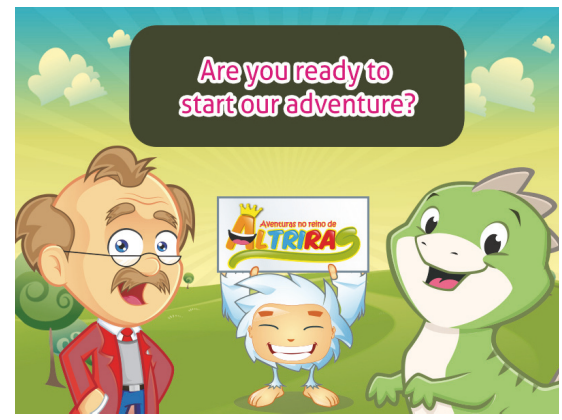

FIgURE 6: Rex welcomes the player.

\section{Results}

The results acquired from the development process of the game, its assessment made by experts, and the usability testing, as well as the effectiveness test performed by the subjects are presented in the following items.

3.1. The Game ALTRIRAS. Figures 4-9 exemplify some graphic interfaces: (Figure 4) home screen; (Figure 5) interface where the child chooses the character Rex (boy) or Tina (girl), who will guide them to select the facial expressions; (Figure 6) Rex welcomes the player; (Figure 7) interface where the wizard of the emotions explains them; (Figure 8) interface that displays the "Emotion/avatar" and expresses the emotions to be trained along the game: ALegria (joy), TRIsteza (sadness), RAiva (anger), and Surpresa (surprise); (Figure 9) images showing some enemies.

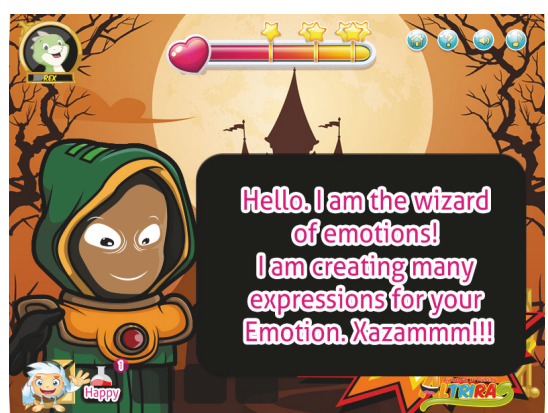

FIgURE 7: The wizard of emotions explains them.

Figure 10 shows the interface of the environment 1, developed in 2D (Isometric), where Rex/Tina will look for some items until reaching the puzzle at the end of the adventure. Figure 11 shows Rex giving instructions to the child about the way to follow. Along the game, even with the possibility of asking information to the inhabitants, the screen shows instructions and messages to the child to help them to reach the end of the way (Figure 12). By exploring the environment, the child gets along with other characters that will inform them not only the way to follow but also some items to find. Therefore, after finding and opening a chest, the player can collect facial expressions or potions of emotions (Figure 13). It is possible to find three features of each facial expressions, associated with emotions, such as eyebrows, eyes, and mouth.

In case the child cannot find any box in that phase, they receive expressions needed to train the avatar (Emotion) at the end of each puzzle. Male and female characters have been used to help practice facial expressions, a brief expression training is also given to the child (Figures 14 and 15), so that they can check their progress (Figure 16).

When selecting the avatar, in the left corner of the screen, it is possible to access the character selection and the expressions already found by Rex (Figure 17). As the child finds the chest, the expression is released (Figure 18) and a different screen displays, as shown in Figure 19. When the child collects all the expressions related to an emotion, they have the chance to train the avatar by clicking and dragging the expression to the avatar's direction, as illustrated in Figure 20.

Figure 21 shows the puzzle interface. By the end of the phase, it is possible to play the puzzle whose objective is to combine the expressions such as joy, sadness, anger, and surprise. When the amount of expressions is completed, the player begins a new level. To complete the levels, the player should match three or more expressions. In this puzzle, the child can match the expressions to enhance the ability of recognizing strategies, standards, and sequences. At the end of a puzzle, the feedback interface pops up (Figures 21(b), 22(a) and 22(b)).

The interfaces and interactive devices presented in the game create a playful environment for children to keep their focus in matching the expressions and emotions. Also, 

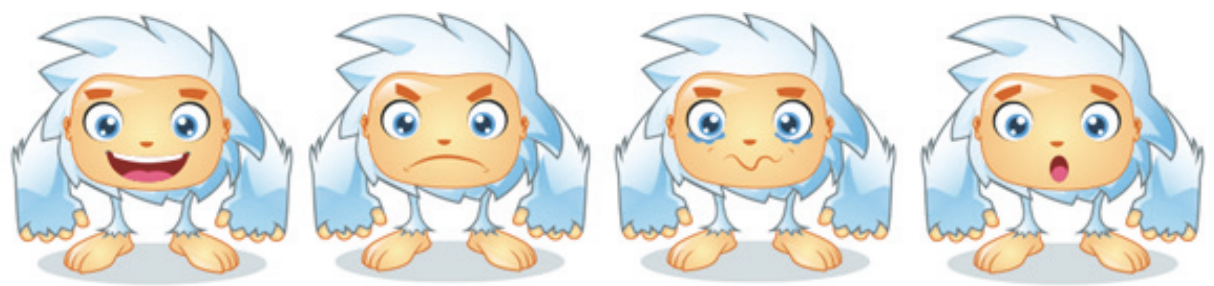

FIGURE 8: Character emotion, variation of the facial expressions [23].

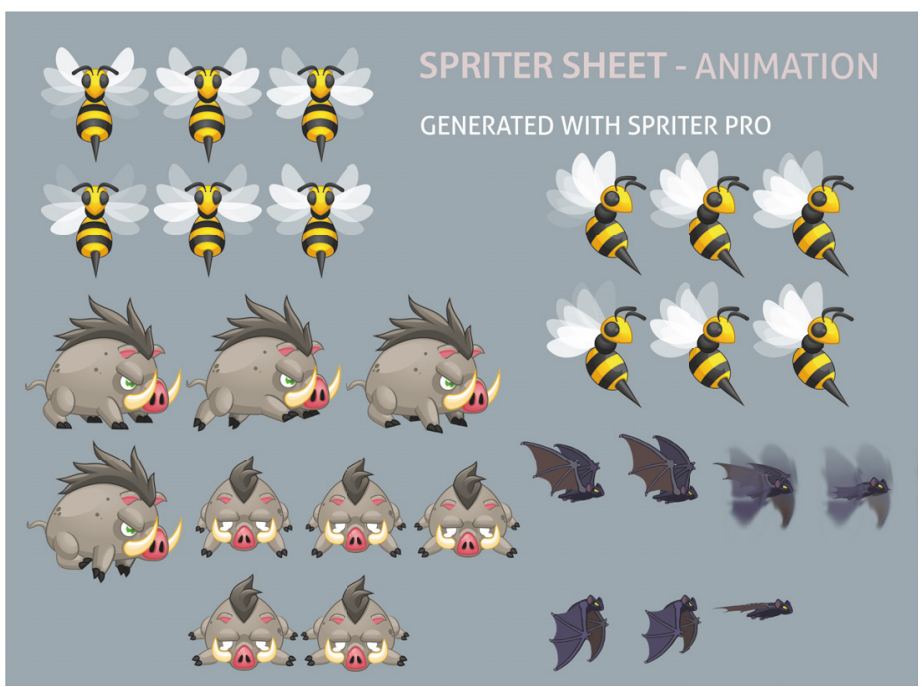

FIgURE 9: Animation (some enemies) from SpriterPro, by BrashMonkey to Unity.

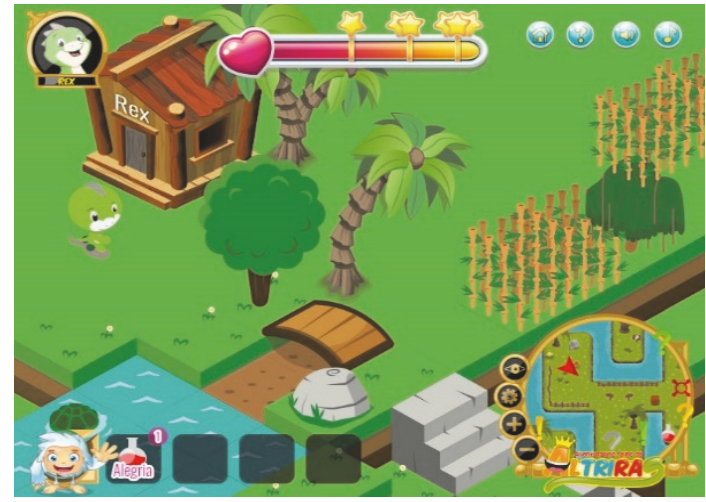

FIGURE 10: Interface of the environment 1.

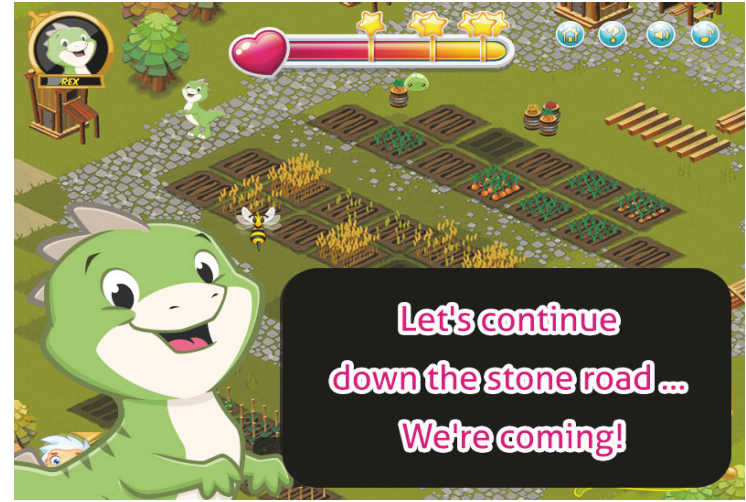

FIGURE 11: Messages of support. choosing a character and customizing it is one more encouragement to play this game, because it helps the players to identify themselves with it.

3.2. Expert Assessment and Usability Testing. Taking into account the evaluation performed by experts for each of the quality components evaluated through the SUS scale, a score was obtained above the SUS questionnaire average; that is, we obtained an overall mean value of $92.5 \pm 8,5$ as may be observed in Figure 23.
In Figure 23, one can notice that the scores were higher than 60 , which means a positive assessment concerning the usability. By calculating the score overall average of all experts, the result obtained was 92.5 (in a 0 to 100 scale). It is above the average as stated by Bangor et al. [41] and indicates a positive assessment regarding the ease of use of the game.

Converting the SUS score obtained by the game ALTRIRAS into adjectives as performed in the Bangor study, it is noted that most experts (75\%) considered the usability of this game as "Excellent", while among the other experts, some of 


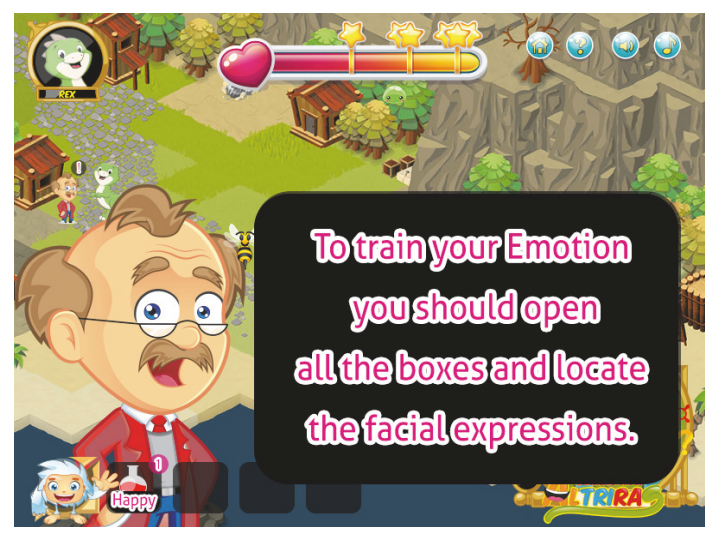

FIGURE 12: Rex interacting with characters of the environment.

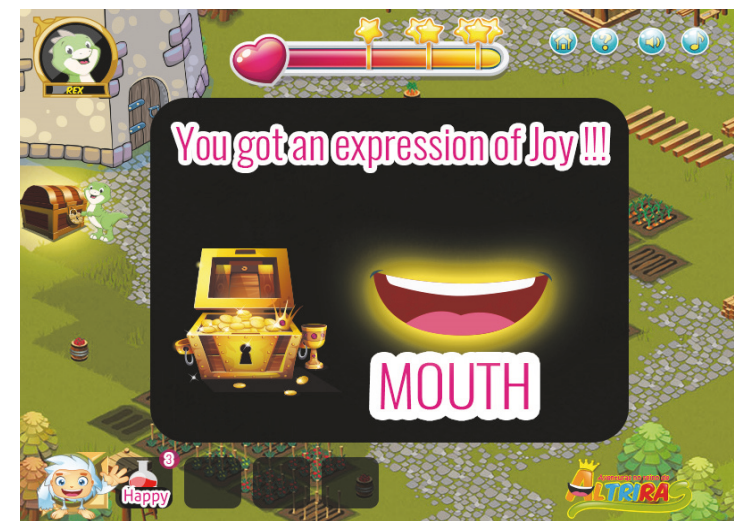

FIGURE 13: Opening of the box and receiving a facial expression.

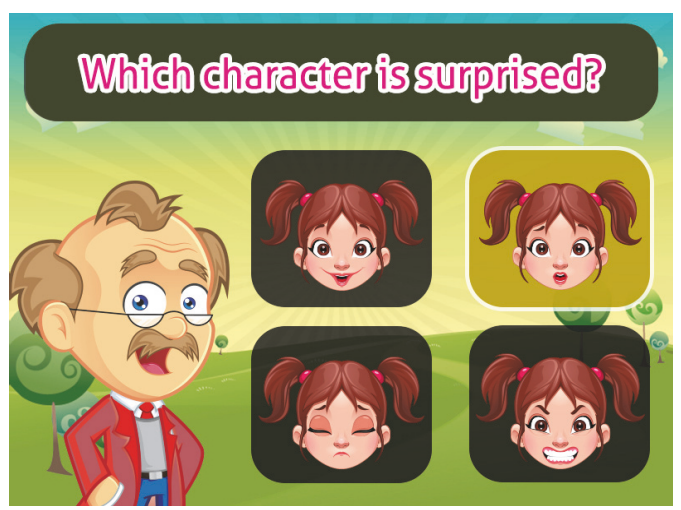

Figure 14: Teaching facial expressions, surprise.

them are considered as "Great" (5\%), "Good" (15\%), and "ok" (5\%).

As stated by [43] it is possible to acknowledge the components of the software quality suggested by Nielsen [39] through the score average results of the SUS questionnaire: ease of learning (questions $3,4,7$, and 10); efficiency (questions 5,6, and 8); data storage (question 2); error reduction (question 6); satisfaction (questions 1, 4, and 9). Table 1 shows the results for the game ALTRIRAS.

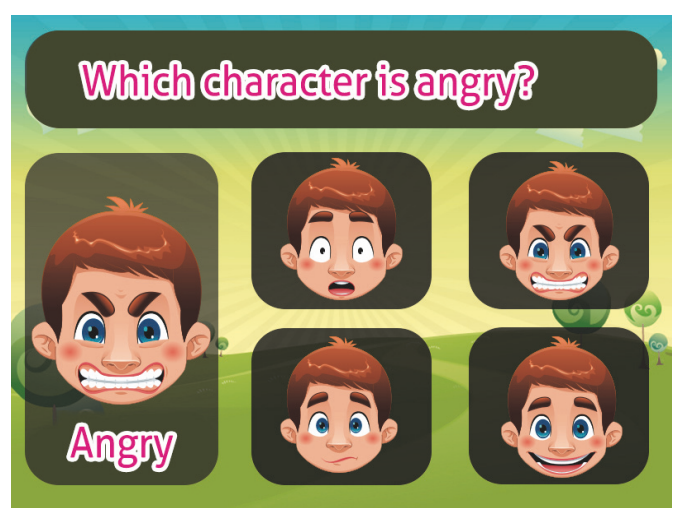

FIGURE 15: Teaching facial expressions, anger.

TABLE 1: Average SUS score referring to the quality components of the game ALTRIRAS-experts.

\begin{tabular}{lc}
\hline Software quality components & SUS Score (0 to 100) \\
\hline Ease of learning & 96.3 \\
Efficiency & 94.7 \\
Ease of storage & 96.0 \\
Minimizing errors & 93.0 \\
Satisfaction & 89.0 \\
\hline
\end{tabular}

Experts also considered the game ALTRIRAS approved in all quality metrics evaluated (graphics, sounds, controls, fun, and animations). According to them, the method meets the psychological and entertainment requirements.

The errors found in the new version were corrected and, according to the psychologists and pedagogues who evaluated it, the game continues to place players in playful situations with the potential to assist them in learning facial expressions, since it stimulates an association between them and emotions.

They agree that the environment puts players in the face of challenges, rules, and limits, because they are delimited in a space, having to follow rules to continue playing and reach a new stage. According to them, the game also works positively the frustration of losing and self-esteem as there are incentive feedback screens and when an incorrect choice occurs the player is made to try again, thus having other chances to get it right. The sound stimuli implemented, in turn, are able to promote the learning of the associative capacities necessary for the recognition of facial expressions.

3.3. Usability and Effectiveness Tests with Non-Disabled Children. Regarding the non-disabled children who performed the test, for each of the quality components evaluated through the SUS scale, a score above the mean of the scale was also obtained, that is, an overall mean value of $91.25 \pm 1.86$ (Figure 24). Taking into account the adjectives proposed by Bangor et al. [41], the usability of the game was considered by most children (57\%) as "Excellent" and others (43\%) as "Best". Besides, Table 2 shows the components of the software quality according to Nielsen [39]. 

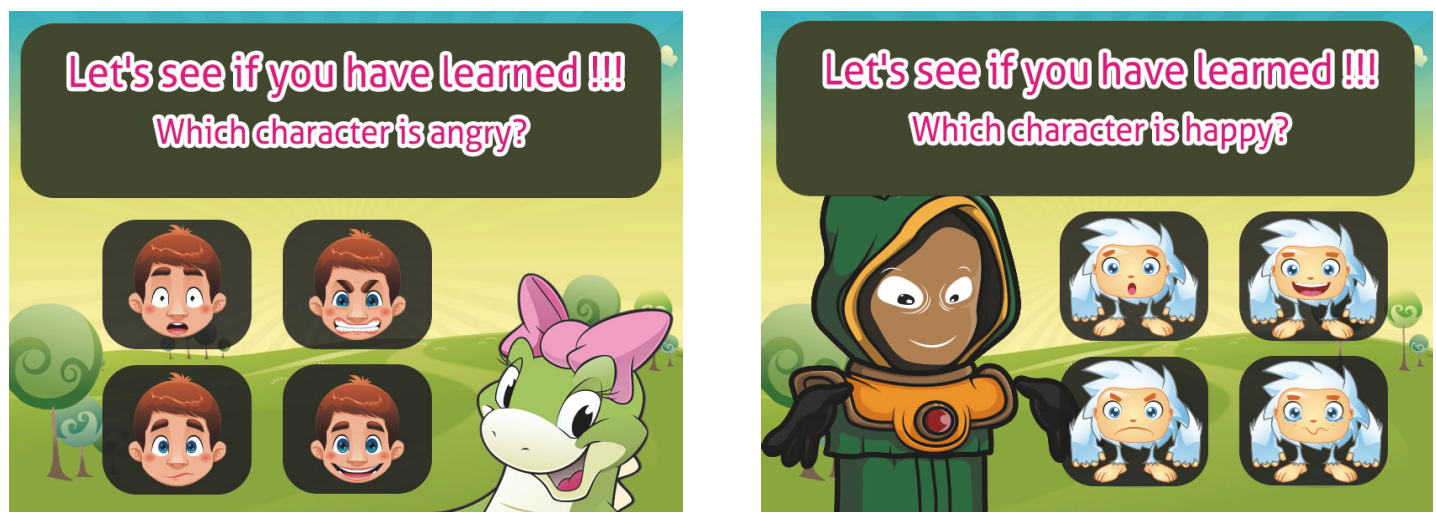

FIGURE 16: Checking learning.

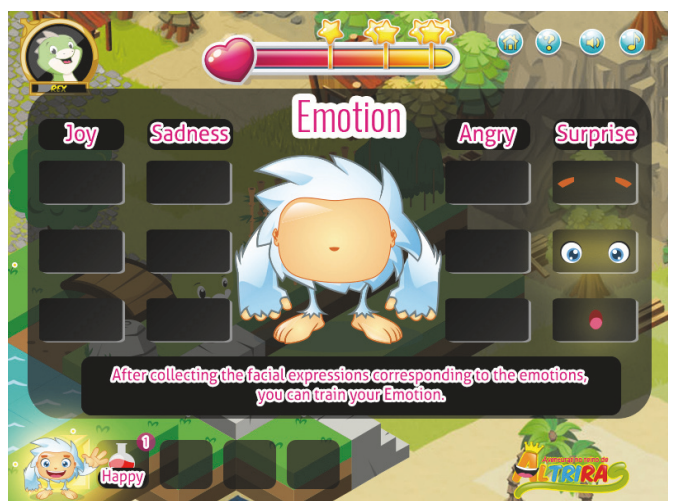

FIgURE 17: Avatar selection.

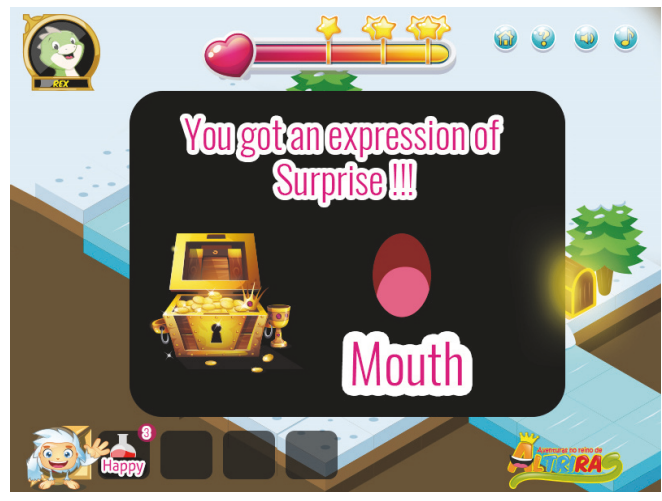

Figure 18: Selected expressions.

TABLE 2: Average SUS score referring to the quality components of the game ALTRIRAS: nondisabled children.

\begin{tabular}{lc}
\hline Software quality components & Score SUS (0 to 100) \\
\hline Ease of learning & 97.14 \\
Efficiency & 94.29 \\
Data storage & 100 \\
Errors reduction & 100 \\
Satisfaction & 86.19 \\
\hline
\end{tabular}

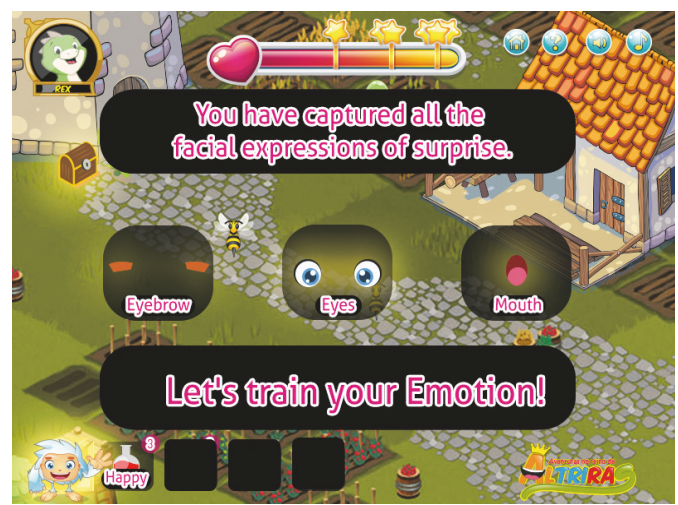

FIGURE 19: Selected expressions.

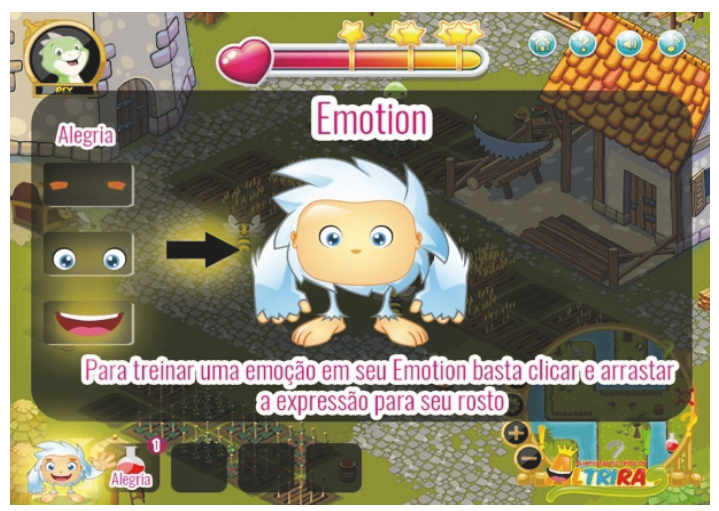

FIgURE 20: Training emotions.

Looking at the graphics and tables with the statistical data presented above, it is noticed that the non-disabled children were more positive regarding the usability evaluation of the game ALTRIRAS. Only 3 children scored below 90 because for the 7th (7th) question ("I would imagine most people would learn to use this application very quickly"), they answered that they were indifferent. However, when we 


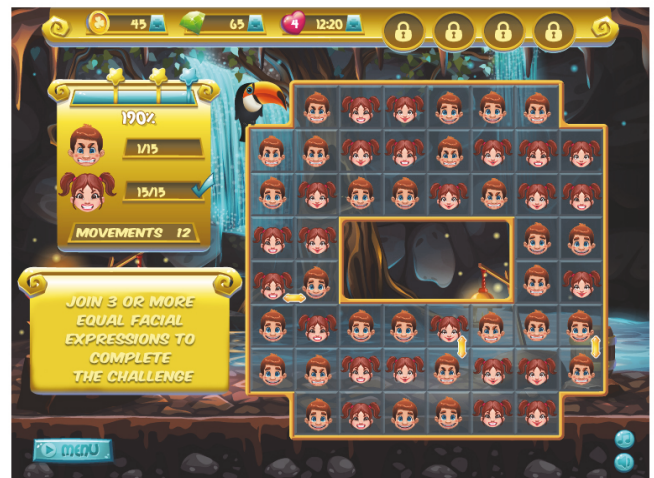

(a)

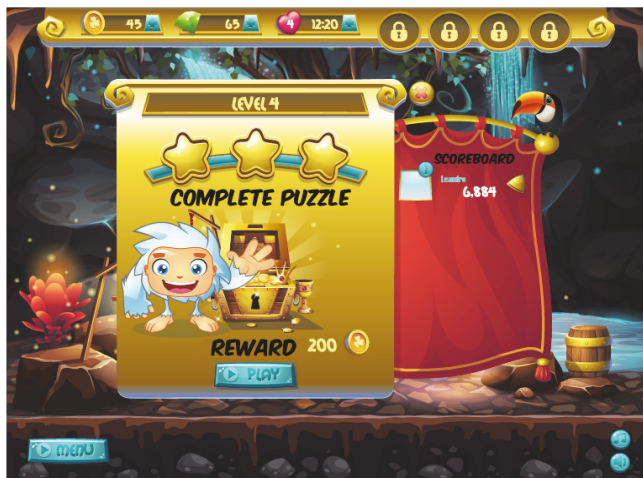

(b)

Figure 21: (a) Matching emotions [23]; (b) feedback interface.

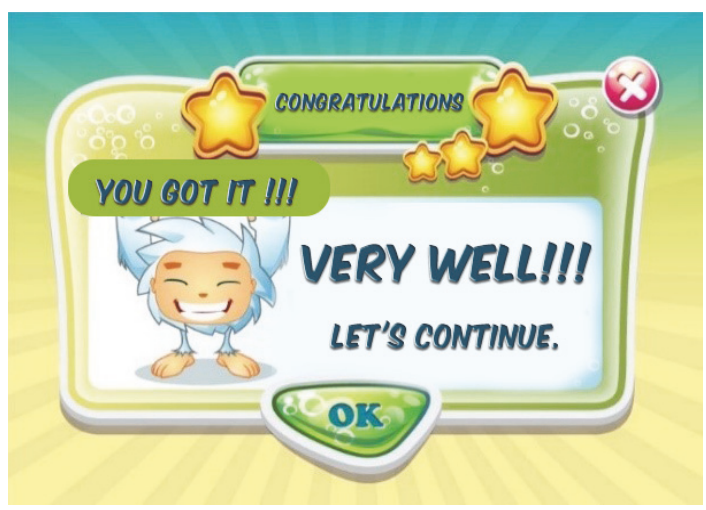

(a)

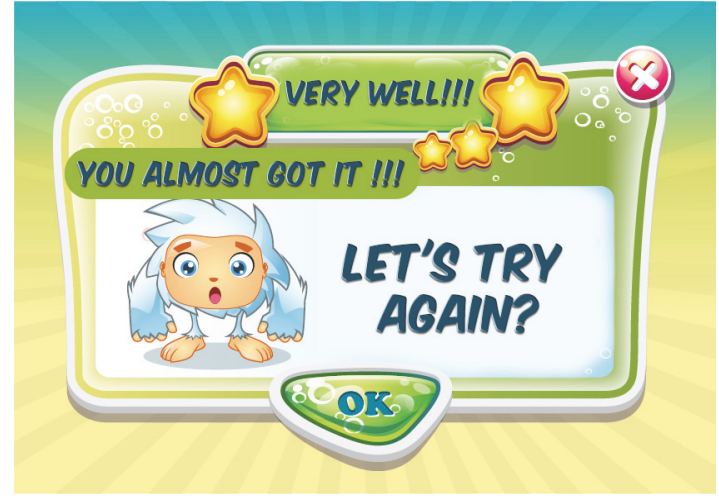

(b)

FIGURE 22: Feedback example: (a) great [23]; (b) try again.

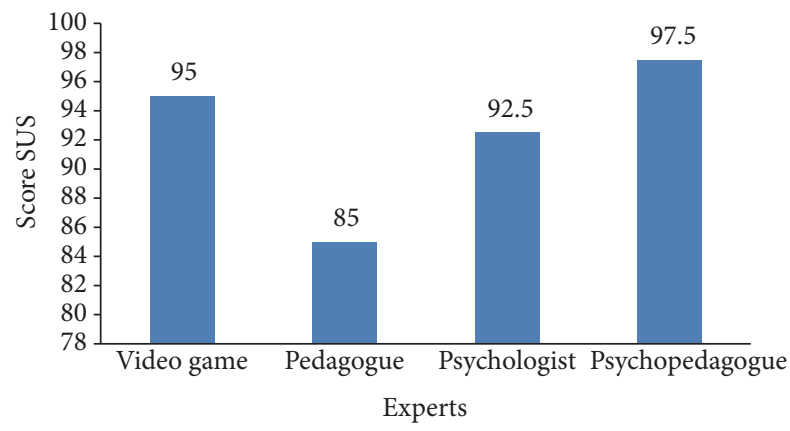

FIGURE 23: Result of the ALTRIRAS usability test performed by the experts.

totalize the responses of all the children for each response, we can see a positive result, as shown in Figure 25.

3.4. Effectiveness Test with Children with ASD. Table 3 presents the answers that children with ASD obtained using the QuizEmotion application before and after the intervention period with the game ALTRIRAS.
According to the applied statistical test, the Wilcoxon test, there was no significant difference between the number of correct answers for children with ASD in the pre- and posttest. As reported by the psychologist, these children presented a marked difficulty, being necessary to insert the game in their routine for a longer period of time so that we could notice a significant difference between before and after the use of our game. Regarding the number of successful answers, the children with ASD only scored $22 \%$ in both tests.

It is noteworthy that we intended to test with 30 children. However, the psychologist focused on the top 10. Due to the difficulty of these children and the need to rethink the intervention protocol, we are only showing the results regarding them.

The scores obtained by non-disabled children and the ones with ASD in the pretest using the QuiZEmotions application were compared with the Kruskal-Wallis statistical test. This comparison resulted in a significant difference between the scores achieved by children without ASD in relation to children with ASD. This difference was already expected due to the difficulty that children with the disability present to recognize emotions and to associate them with facial expressions. 


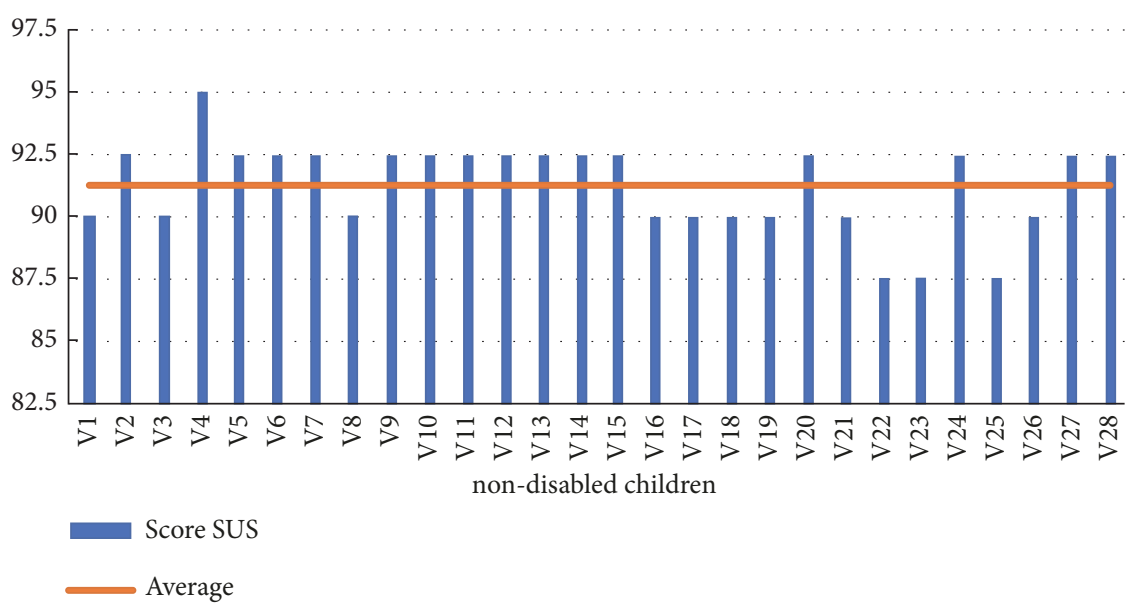

FIGURE 24: Result of the ALTRIRAS usability test performed by the non-disabled children.

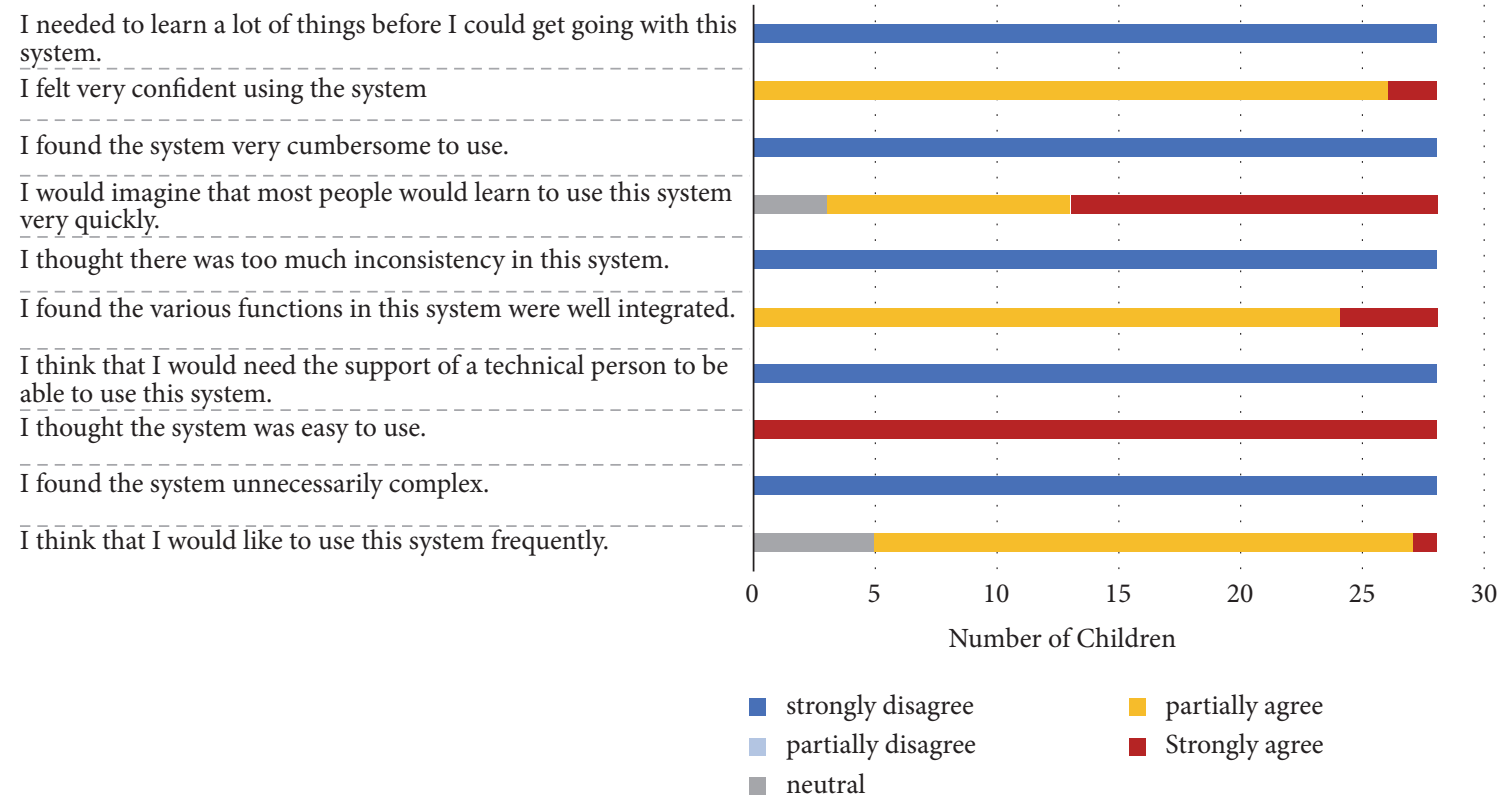

FIGURE 25: Overall level of agreement of neurotypical children, with usability the game ALTRIRAS measured through the SUS scale questions.

TABLE 3: Summary of correct answers for children with ASD when they used the QuizEmotion application in the pre- and posttest.

\begin{tabular}{lcc}
\hline Autistic children & Pre-test (hits) & Post-test (hits) \\
\hline Student -1 & 1 & 2 \\
Student -2 & 0 & 0 \\
Student -3 & 0 & 3 \\
Student -4 & 1 & 0 \\
Student -5 & 2 & 0 \\
Student -6 & 1 & 2 \\
Student -7 & 1 & 0 \\
Student -8 & 2 & 1 \\
Student -9 & 1 & 2 \\
Student -10 & 2 & 1 \\
\hline
\end{tabular}




\section{Discussion}

RPG games are based on social interaction [44] and since the psychological development of an individual is defined by their social interactions [45], these games represent an outstanding resource in the psychological development of the players, especially in children with ASD to whom RPG adventure games are suitable for [44].

Having that said, the characters from the game were exclusively designed in a cartoon style which appeals to the children's attention. According to literature, cartoons are an efficient resource to communicate something to the children. "The coloured moving images first capture children's attention before they understand any message, providing them a world full of symbols that reflect complex concepts to explain to a young child" [46, 47].

The computer game was designed in a playful and modern atmosphere to attract children's attention. The characters Rex and Tina with dinosaur features will give them the guidelines along the facial expression choices (joy, sadness, anger, and surprise).

Players improve their self-esteem when they choose their favourite character, what enhances socialization [48]. To grant the several kinds of preferences, the web environment provided another character to vary and to upgrade the player's self-esteem [49].

Facial expressions associated with the feelings of joy, surprise, sadness, and anger are essential for understanding the other ones, such as: anxiety, distress, affection, curiosity, guilty, doubt, regret, laziness, concern, shyness, and shame. All these feelings are important to the socialization and communication process of the individuals, particularly for the children with ASD [20].

Different kinds of educational approaches enable educators to reach their goals and pass on their expertise. The game ALTRIRAS helps to enhance some learning skills in children with ASD, such as social interactions, motor skills, association of facial expressions to feelings, and reasoning.

It is expected that the game offers the users a constructive attitude connecting reasoning, feelings and actions. Results showed that the game matches psychological, functional, and nonfunctional specifications settled at the beginning of the project.

The virtual setting and the interactive tools provide children with an amusing atmosphere, capturing their attention to accomplish the tasks. ASD children feel delighted with the colourful interfaces and pleasant objects like dinosaurs, trains, and continuously moving images.

The sounds, the spoken warnings, and the written and the picture feedbacks play an important role to make children have a better game immersion. The three web environments and the character's choice stimulate gameplay, once their features appeal to children with ASD [48].

Mostly, games operate with mouse commands and touchscreen technology due to their user-friendly interface, which is most suitable for children. However, besides the two technologies included in the method, the keyboard arrow keys also allow navigation as a third option.
The use quality tests (usability and functionality) checked if the action sequences as well as feedbacks had been executed as expected.

Computer games experts have appreciated ALTRIRAS characteristics, especially because of its attractive web environment, graphic interfaces (colours, animation, among other features), and the challenging puzzles. Besides being an educational game, ALTRIRAS is also an entertainment game due to the features mentioned above.

The 3D unit used to code the game has proven to be suitable since it allows data export to all market available platforms and mobile devices. As it was designed by vector graphics, which expand its accessibility, it is easy to play and does not need a broadband Internet connection.

When compared to other educational, entertainment, or commercial software or even with the ones in specific literature, it can be concluded that the game "Adventures in ALTRIRAS Kingdom" leaves nothing to be desired to any of them, since it has important features such as graphic interface, effective mechanisms, feedbacks, attractiveness, usability, gameplay, and Internet access. It allows children with ASD to identify themselves with the main character, designed to please them, besides motivating them to set puzzles and exploit surroundings, which was not observed in any of the studied software.

However, when compared to specific educational software for children with ASD like LIFEisGame of the University of Porto, in Portugal, its assumptions were partially filled; the usual software tests met the expectations, while the effectiveness tests performed with these children will be improved in future researches considering an increase in the number of children and the sessions for intervention with the ALTRIRAS game, as well as the duration of each session.

After the tests with 10 children with ASD and 28 nondisabled children, it was observed that both the pre-and posttest instruments and the game itself were considered interesting and useful. However, what needs to be done is to generate a new strategy of application of the game to cover the real difficulty of children with ASD. For non-disabled children, the time of interaction with the applications and the game served as entertainment. It also helped us to conclude that it is of fundamental importance to choose the image set to associate the facial expressions with the emotions.

It is important to emphasize the increase in the knowledge about the use of games based on the format RPG for children with ASD, mainly regarding the best strategy for the accomplishment of the intervention with this type of application and target public.

Future effectiveness tests with children will allow us to assess the complexity of the implemented actions, whether the number of options fits the difficulty level of children with ASD or it will be necessary to create different ones according to their neurological commitment degree.

Besides that, the facial expressions implemented in the game do not cover all the other emotions also important and necessary to expand the social interaction of children with ASD. They show the tool potential and are an important starting point to help experts to suggest which facial expressions are really important to these children. 
New facial expressions or their web environment changes could be done as a result of new demands or feedbacks from the user of the game ALTRIRAS.

\section{Conclusions}

The construction of the game ALTRIRAS followed the functional, nonfunctional, psychological, pedagogical, and entertaining requirements through researches in specific literature, in addition to being assisted by a multidisciplinary team.

A pilot evaluation of the game ALTRIRAS was conducted and the results were positive, although we concluded that a longer intervention period will benefit children with ASD and perhaps allow a more significant evolution to be observed.

Experts also approved the game in the usability test (taking into account graphics, sound, control, entertainment, and animation). After conducting the pilot effectiveness test with 10 children with ASD and 28 children with neurotypical development, both the pre- and posttest instrument and the ALTRIRAS game were considered interesting and useful.

As stated by the multidisciplinary team, the game ALTRIRAS contemplates all the necessary requirements to be considered as an entertainment game and increase social interaction according to the objectives of the project. Its main contribution is to help children with ASD associate basic feelings to their corresponding facial expressions. The development of the game ALTRIRAS leads to a scientific challenge putting together a team of experts in Psychology, Education, Computing, Digital Games, Semiotic, Graphic Design, and Biomedical Engineering. However, it is only a prototype to help reducing the Autism Spectrum Disorder.

The techniques to develop the game are the same ones used in Institutions like AMA and AEE, in the municipal education system. After using this game, children are expected to enlarge their communication and perception skills and have a better life quality.

We advance in the knowledge about the use of games based on RPG format for individuals with ASD, with the degree of difficulty that we are facing, mainly in what refers to the best strategy to carry out the intervention. As emphasized by the psychologist, who assisted us in the pilot test, the children with ASD would benefit more if our game were inserted in their routine, being used daily and for a period superior to that applied in the pilot test. While for nondisabled children, the time of interaction with the applications and the game served as entertainment. Additionally, the pilot test also helped us to conclude that it is of fundamental importance the choose of the image set for associating the facial expressions to the four basic emotions. Therefore, we will continue our research considering the observations of this psychologist in order to actually cover the real difficulty of children with ASD.

\section{Data Availability}

The data used to support the findings of this study are included within the article.

\section{Conflicts of Interest}

The authors declare that there are no conflicts of interest regarding the publication of this paper

\section{Acknowledgments}

The authors thank everyone who took part in this survey; autism or nonautism children, their parents who allowed their participation, the multidisciplinary team from the schools where these children study, and all the experts who gave their opinions about this project. Funding for this project was obtained from the Sao Paulo Research Foundation (Brazil) FAPESP (Grant no. 2015/12248-2), University of Mogi das Cruzes (UMC), Coordination of Improvement of Higher-Level Personnel (CAPES), and National Council for Scientific and Technological Development (CNPq).

\section{References}

[1] C. A. Gadia, R. Tuchman, and N. T. Rotta, "Autism and pervasive developmental disorders," Jornal de Pediatria, vol. 80, no. 2, pp. 583-594, 2004.

[2] A. Klin, "Autism and Asperger syndrome: an overview," Revista Brasileira de Psiquiatria, vol. 28, Supl I, no. 1, pp. 3-11, 2006.

[3] A. Pereira, R. S. Riesgo, and M. B. Wagner, "Autismo infantil: tradução e validação da childhood autism rating scale para uso no brasil," Jornal de Pediatria, vol. 84, no. 6, pp. 487-494, 2008.

[4] B. Scassellati, H. Admoni, and M. Matarić, "Robots for use in autism research," Annual Review of Biomedical Engineering, vol. 14, no. 1, pp. 275-294, 2012.

[5] W. W. Hay, M. J. Levin, R. R. Deterding, and J. M. SonDheimer, "Current diagnóstico e tratamento," in Pediatria, pp. 127-128, McGraw Hill, Brasil, 2012.

[6] H. M. Zakari, M. Ma, and D. Simmons, "A review of serious games for children with autism spectrum disorders (ASD)," in International Conference on Serious Games Development and Applications, vol. 8778 of Lecture Notes in Computer Science, pp. 93-106, Springer International Publishing, Cham, Switzerland, 2014.

[7] American Psychiatric Association, Diagnostic and Statistical Manual of Mental Disorders, (DSM-5), American Psychiatric Pub, 5th edition, 2013.

[8] E. Rellini, D. Tortolani, S. Trillo, S. Carbone, and F. Montecchi, "Childhood autism rating scale (CARS) and autism behavior checklist $(\mathrm{ABC})$ correspondence and conflicts with DSM-IV criteria in diagnosis of autism," Journal of Autism and Developmental Disorders, vol. 34, no. 6, pp. 703-708, 2004.

[9] R. Muhle, S. V. Trentacoste, and I. Rapin, "The genetics of autism.", Pediatrics, vol. 113, no. 5, pp. e472-486, 2004.

[10] J. Baio, "Prevalence of autism spectrum disorders: autism and developmental disabilities monitoring network, 14 sites, united states," in Morbidity and Mortality Weekly Report. Surveillance Summaries, Centers for Disease Control and Prevention, vol. 61, pp. 1546-0738, Centers for Disease Control and Prevention, 2008.

[11] K. L. Allen, S. M. Byrne, W. H. Oddy, and R. D. Crosby, "DSM-IV-TR and DSM-5 eating disorders in adolescents: Prevalence, stability, and psychosocial correlates in a population-based sample of male and female adolescents," 
Journal of Abnormal Psychology, vol. 122, no. 3, pp. 720-732, 2013.

[12] "Associação Brasileira De Autismo (ABRA)/ Brazilian Autism Association," 2015, http://www.autismo.org.br/.

[13] "Associação De Amigos Do Autista (AMA) / Autista Friends Association," 2015, http://www.ama.org.br/.

[14] K. Van Naarden Braun, D. Christensen, N. Doernberg et al., "Trends in the prevalence of autism spectrum disorder, cerebral palsy, hearing loss, intellectual disability, and vision impairment, metropolitan Atlanta, 1991-2010," PLoS ONE, vol. 10, no. 4, 2015.

[15] C. E. Izard, "Facial expressions and the regulation of emotions," Journal of Personality and Social Psychology, vol. 58, no. 3, pp. 487-498, 1990.

[16] D. P. Kennedy and R. Adolphs, "Perception of emotions from facial expressions in high-functioning adults with autism," Neuropsychologia, vol. 50, no. 14, pp. 3313-3319, 2012.

[17] G. Charbonneau, A. Bertone, F. Lepore et al., "Multilevel alterations in the processing of audio-visual emotion expressions in autism spectrum disorders," Neuropsychologia, vol. 51, no. 5, pp. 1002-1010, 2013.

[18] J. W. Tanaka, J. M. Wolf, C. Klaiman et al., "The perception and identification of facial emotions in individuals with autism spectrum disorders using the let's face it! emotion skills battery," Journal of Child Psychology and Psychiatry and Allied Disciplines, vol. 53, no. 12, pp. 1259-1267, 2012.

[19] C. Atul and J. Anurag, "Survey on human face expression recognition," in Proceedings of the International Journal of Computer Science and Mobile Computing, vol. 3, pp. 20-24, 2014.

[20] F. B. Assumpção Jr, M. H. Sprovieri, E. Kuczynski, and V. Farinha, "Reconhecimento facial e autismo," Arquivos de NeuroPsiquiatria, vol. 57, no. 4, pp. 944-949, 1999.

[21] L. S. Machado, R. M. Moraes, and F. L. Nunes, "Serious games para saúde e treinamento imersivo," Abordagens Práticas de Realidade Virtual e Aumentada, vol. 1, pp. 31-60, 2009.

[22] E. Guerra and F. Furtado, "A proposal software for multidisciplinary treatment of autistic children," in Proceedings of the 8th Iberian Conference on Information Systems and Technologies, CISTI 2013, IEEE, pp. 1-6, Portugal, June 2013.

[23] L. M. Almeida and M. A. S. Bissaco, "Método computadorizado para ensinar crianças com transtorno do espectro autista a reconhecer emoções," in Anais do XXV Congresso Brasileiro de Engenharia Biomédica, Foz do Iguaçu, Brazil, 2016.

[24] C. Eichenberg, G. Grabmayer, and N. Green, "Acceptance of serious games in psychotherapy: an inquiry into the stance of therapists and patients," Telemedicine and e-Health, vol. 22, no. 11, pp. 945-951, 2016.

[25] A. Yussof, A Conceptual Framework for Serious Games and its Validation [Thesis for the Degree of Doctor of Philosophy], Faculty of Engineering, Sciences and Mathematics School of Electronics and Computer Science - University of Southampton, 2010.

[26] G. Acampora, D. J. Cook, P. Rashidi, and A. V. Vasilakos, "A survey on ambient intelligence in healthcare," Proceedings of the IEEE Institute of Electrical and Electronics Engineers, vol. 101, no. 2, pp. 2470-2494, 2013.

[27] T. Mondéjar, R. Hervás, E. Johnson, C. Gutierrez, and J. M. Latorre, "Correlation between videogame mechanics and executive functions through EEG analysis," Journal of Biomedical Informatics, vol. 63, pp. 131-140, 2016.

[28] D. Bavelier, C. Shawn Green, A. Pouget, and P. Schrater, "Brain plasticity through the life span: Learning to learn and action video games," Annual Review of Neuroscience, vol. 35, pp. 391416, 2012.

[29] T. Fernandes, S. Alves, J. Miranda, C. Queirós, and V. Orvalho, "LIFEisGAME: a facial character animation system to help recognize facial expressions," in Enterprise Information Systems, vol. 221 of Communications in Computer and Information Science, pp. 423-432, Springer, Berlin, Germany, 2011.

[30] P. Winoto, V. L. Cao, and E. M. Tang, "A highly customizable parent-child word-learning mobile game for chinese children with autism," in Proceedings of the International Conference on Universal Access in Human-Computer Interaction, vol. 10277 of Lecture Notes in Computer Science, pp. 545-554, Springer International Publishing, Cham, Switzerland, 2017.

[31] E. Boutsika, "Kinect in education: a proposal for children with autism," Procedia Computer Science, vol. 27, pp. 123-129, 2014.

[32] L. Seletos, Comparing Native and Cross-Platform Development Tablet Environments Based on an Application for Autism, Stetson University, 2012.

[33] I. Sommerville, Software Engineering, Pearson Addison Wesley, São Paulo, Brazil, 8th edition, 2007.

[34] R. S. Pressman, Software Engineering, McGraw Hill, Brasil, 2011.

[35] S. Laitinen, "Better games through usability evalution and testing," 2005.

[36] M. Azuma, "SQuaRE: the next generation of the ISO/IEC 9126 and 14598 international standards series on software product quality," in Proceedings of the ESCOM (European Software Control and Metrics conference), pp. 337-346, 2001.

[37] Associação Brasileira De Normas Técnicas, NBR ISO/IEC 91261: Engenharia de software: qualidade de produto: parte 1: modelo de qualidade, 2003.

[38] J. Nielsen, Usability Engineering, Academic Press, London, UK, 1994.

[39] J. Nielsen, "Usability 101: introduction to usability," 2012, http:// http://www.nngroup.com/articles/usability-101-introduction-tousability/.

[40] J. Brooke, "SUS-A quick and dirty usability scale," Usability Evaluation in Industry, vol. 189, no. 194, pp. 4-7, 1996.

[41] A. Bangor, P. T. Kortum, and J. T. Miller, "An empirical evaluation of the system usability scale," International Journal of Human-Computer Interaction, vol. 24, no. 6, pp. 574-594, 2008.

[42] D. P. da Silva, F. C. Amate, F. R. M. Basile, C. B. Filho, S. C. M. Rodrigues, and M. A. S. Bissaco, "AACVOX: Mobile application for augmentative alternative communication to help people with speech disorder and motor impairment," Research on Biomedical Engineering, vol. 34, no. 2, pp. 166-175, 2018.

[43] J. M. Tenório, A. D. Hummel, F. M. Cohrs, V. L. Sdepanian, I. T. Pisa, and H. De Fátima Marin, "Artificial intelligence techniques applied to the development of a decision-support system for diagnosing celiac disease," International Journal of Medical Informatics, vol. 80, no. 11, pp. 793-802, 2011.

[44] J. R. Bittencourt and L. M. Giraffa, "Role-playing games, educação e jogos computadorizados na cibercultura," I Simpósio de RPG em Educação, p. 14, 2003.

[45] L. S. Vygotsky et al., "Aprendizagem e desenvolvimento intelectual na idade escolar," in Linguagem, Desenvolvimento E Aprendizagem, vol. 10, pp. 103-117, 1988.

[46] K. Habib and T. Soliman, "Cartoons' effect in changing children mental response and behavior," Open Journal of Social Sciences, vol. 3, no. 9, pp. 248-264, 2015. 
[47] S. Rai, B. Waskel, S. Sakalle, S. Dixit, and R. Mahore, "Effects of cartoon programs on behavioural, habitual and communicative changes in children," International Journal of Community Medicine and Public Health, vol. 3, no. 6, pp. 1375-1378, 2017.

[48] A. M. D. Lima, Ambiente virtual para auxiliar a aprendizagem de meninas com dificuldade de leitura [Tese de Doutorado em Engenharia Biomédica], Universidade de Mogi das Cruzes, 2010.

[49] Y. B. Kafai, D. A. Fields, and M. S. Cook, "Your second selves: resources, agency, and constraints in avatar designs and identity play in a tween virtual world," in Proceedings of the 3 rd Digital Games Research Association International Conference: "Situated Play”, DiGRA 2007, pp. 31-39, Japan, September 2007. 


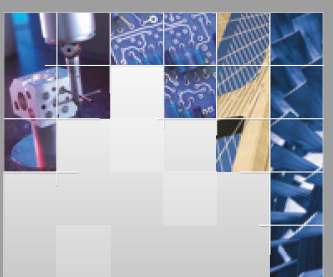

\section{Enfincering}
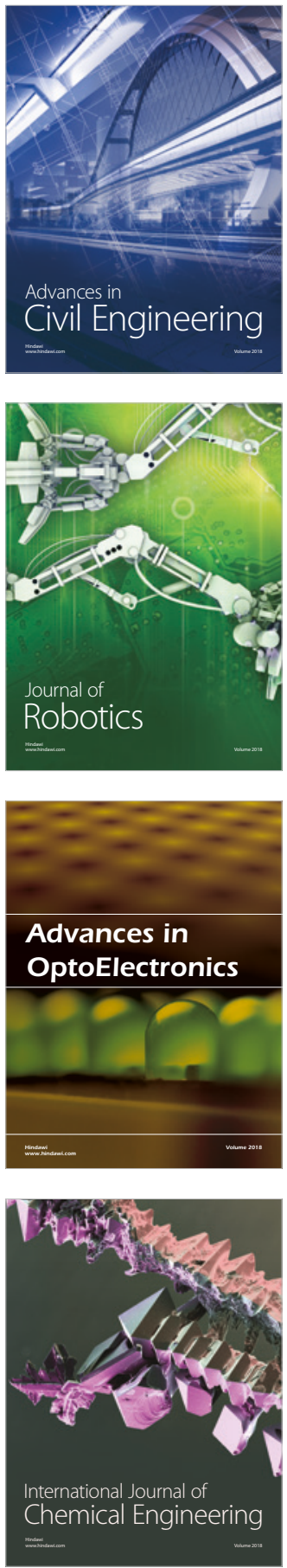

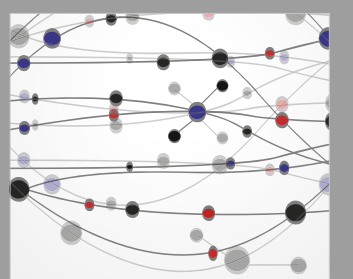

\section{Rotating \\ Machinery}

The Scientific World Journal

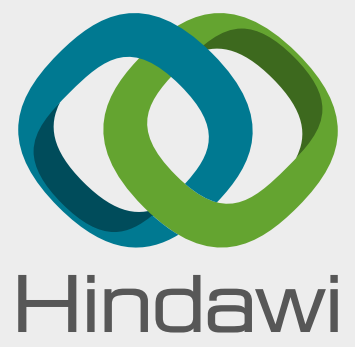

Submit your manuscripts at

www.hindawi.com
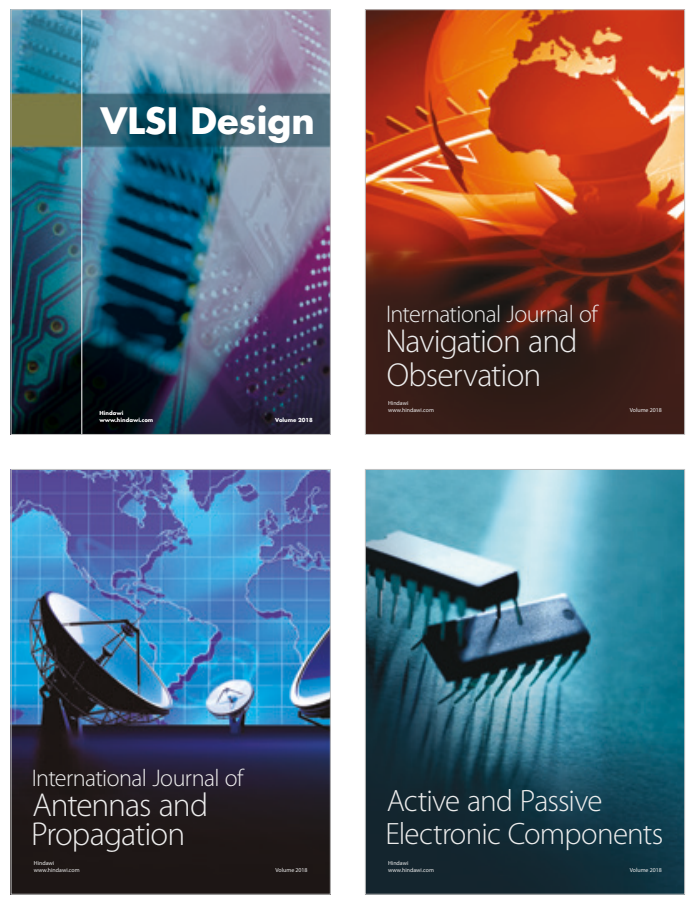
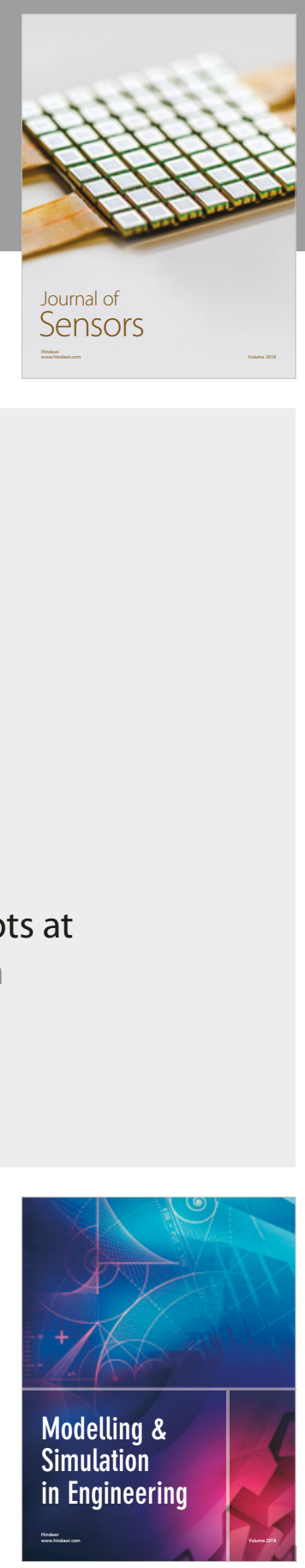

\section{Advances \\ Multimedia}
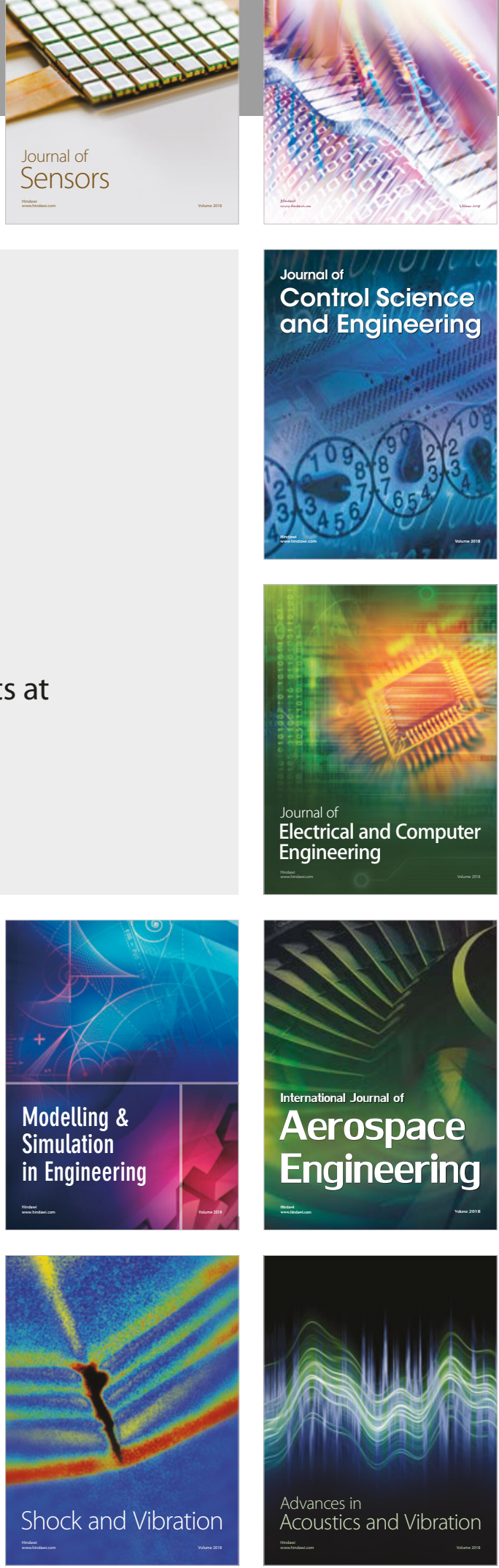